\title{
Dermatological Aspects of Infections Caused By Endotoxins In Teeth With Necrotic Pulps And Apical Periodontitis
}

Daniel Jiménez Zaragoza1*, Jorge Paredes Vieyra2, Francisco Javier Jiménez Enríquez3

${ }^{1}$ Médico residente. Instituto Mexicano del Seguro Social, Hospital General Regional \#45

Guadalajara Jalisco, Mexico

${ }^{2}$ Endodontist, Endodontic department, Universidad Autonóma de Baja California.

${ }^{3}$ Oral Surgeon, Oral Surgery department Universidad Autonóma de Baja California.

*Corresponding Author: Daniel Jiménez Zaragoza MD, Médico residente. Instituto Mexicano del Seguro Social, Hospital General Regional \#45 Guadalajara Jalisco, Mexico

Received date: May 23, 2021; Accepted date: May 27, 2021; Published date: June 04, 2021

Citation: Daniel Jiménez Zaragoza, Jorge Paredes Vieyra, Francisco Javier Jiménez Enríquez (2021) Dermatological Aspects of Infections Caused By Endotoxins In Teeth With Necrotic Pulps And Apical Periodontitis. Journal of Dermatology and Dermatitis. 6(1); Doi:10.31579/2578-8949/076

Copyright: (C) 2021 Daniel Jiménez Zaragoza, This is an open-access article distributed under the terms of The Creative Commons. Attribution License, which permits unrestricted use, distribution, and reproduction in any medium, provided the original author and source are credited.

\begin{abstract}
:
Aim: To report an uncommon case of an extraoral sinus tract of the facial region caused by a tooth with an acute apical abscess in the mandible.

Case report: Established on oral examination and radiographic examination, an Acute Apical Abscess (cellulitis/phlegmon) of tooth 47 was diagnosed, which had resulted in a cutaneous sinus tract. The continuous purulent discharge of the sinus tract in the facial right region ceased after drainage and extraction of tooth 47.

Conclusion: It is challenging to diagnose and identify a cutaneous draining sinus tract of dental origin. Thus, treatment of skin lesions of the face (impetigo), and neck odontogenic infections should always be considered. Clinical and radiographic dental examinations can identify the tooth involved.

Keywords: acute apical abscess; cellulitis; phlegmon; impetigo
\end{abstract}

\section{Introduction}

Chronic periapical inflammation drains along the path of least resistance, which commonly terminates in the form of a sinus tract, intraorally vestibular to the affected teeth [1]. However, depending on the relation between the localization of the periapical lesion and the facial muscles and fasciae, sinus tracts may drain by facial tissues [2]. Maxillary teeth drain extra orally when the infection is localized above, and in the mandible when the infection is localized below the muscle and fascia attachments [1].

The microorganisms that generate cavities, cause manifestations that if the patient does not attend soon, become chronic or aggressive and can generate problems in gums, bone, and facial tissues [3]. Therefore, this type of injury should be avoided, seeking the maximum elimination or reduction of microorganisms so that the treatment avoids damage to the surrounding tissues [4]. Reducing microbes and their by-products from the tooth prevents them from entering the apical area and draining into soft tissues of the face [5, 6].

Gram-negative anaerobic bacteria are the producers of lipopolysaccharides (LPS), called endotoxins [7]. Endotoxin is made up of polysaccharides, lipids, and proteins, where lipid A can generate its toxic consequences in soft tissues. LPS is released during or after the death or reproduction of bacteria [8,9]. This clinical condition is present in a case of Acute Apical Abscess (cellulitis/phlegmon).

Endotoxins stimulate the discharge of competent cells, causing directly biological and immunological events, leading to an inflammatory process of apical bone resorption [10].
The reduction of bacteria and biofilms is achieved by treating the dental lesion or radically extracting the tooth [11]. A sinus tract or fistula is an abnormal canal that originates or ends in an opening. An orofacial fistula is a pathological communication between the cutaneous surface of the face and the oral cavity $[6,7]$.

Tracts occur more frequently due to periapical lesions caused by mandibular teeth with pulp problems with a high incidence than those observed in the maxilla [12].

This pathway can go from an internal cavity or organ to the surface of the body.

Sinus tracts of dental origin can be a diagnostic problem for the clinician due to their appearance and opening in the skin and, occasionally, asymptomatic in their onset.

Dental infections, salivary gland injuries, neoplasms, and developmental injuries have been reported to cause oral skin fistulas, neck fistulas, and intraoral fistulas [2,3].

The possible differential diagnosis of a cutaneous draining sinus tract includes infected cyst, deep fungal infection, skin lesions such as furuncles [8], congenital fistula [13], salivary gland fistula [14], traumatic and iatrogenic lesions [15-16], osteomyelitis [17], tuberculosis [18], neoplasia [19-20], and actinomycosis [21].

The presented case reports an uncommon event of an extraoral sinus tract of the facial region caused by a tooth with an acute apical abscess in the mandible. 


\section{Case report}

\section{Anamnesis and medical history}

The 36-year-old woman attended the Specialized Dermatology Clinic for a persistent skin lesion located on the right side of the cheek. The patient claimed that the lesion had been present for at least 7 months.

Skin biopsies and histopathological examinations were performed twice. The tentative diagnosis of lymphadenoma was disproved and no signs of malignancy were detected. A different diagnosis of 'mechanical manipulation', was proposed. The patient was referred to the Department of Oral Surgery of the Dental School to examine for a possible dental infection.

A panoramic radiograph revealed deep destruction and a periapical radiolucent area on tooth 47 . The sinus tract was active with drainage of pus associated with severe pain. The patient presented acute symptoms of pain and tension in the skin in the area due to the gradual enlargement of the lesion. The skin lesion was associated with a considerable increase in temperature.

The salivation of the submandibular gland was regular. The patient was referred to the Oral Surgery Department to solve her problem. Oral inspection revealed insufficient glass ionomer cement restoration on tooth 47.

\section{Radiographic examination}

The panoramic radiograph taken revealed a considerable periapical radiolucent area associated with tooth 47 . The periapical radiograph on the right side showed the sinus tract through a gutta-percha cone. The radiograph of tooth 47 showed deep interproximal caries (Figure. 1 and 2).

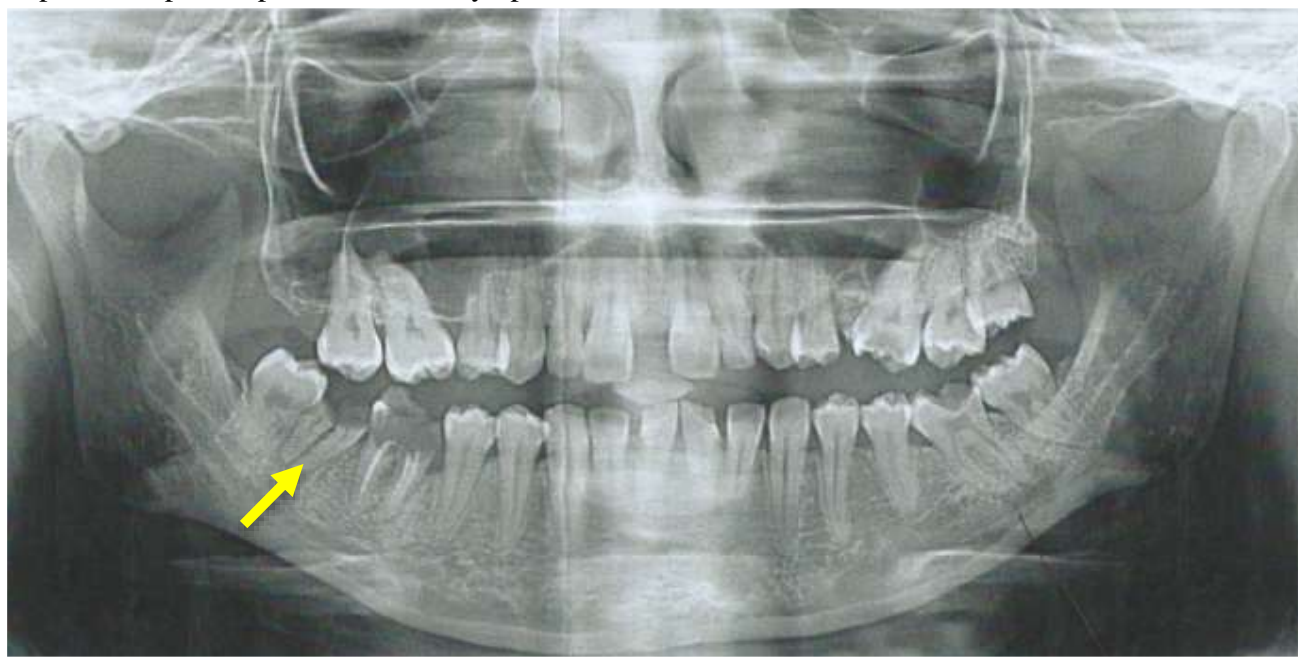

Figure 1: The panoramic radiograph taken revealed a considerable periapical radiolucent area associated with tooth 47

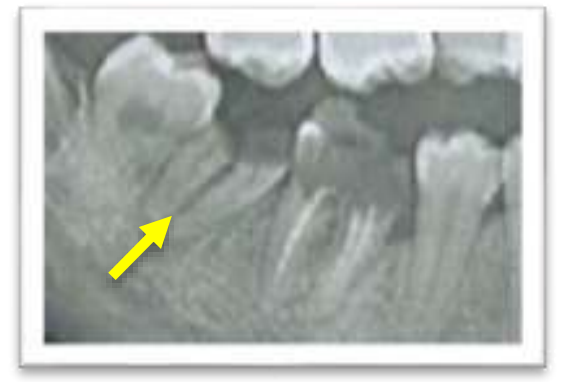

Figure 2: Periapical radiograph indicates the apical lesion of tooth 47; and reveals deep caries.

\section{Microbiological diagnosis}

Biopsy of the area revealed some Streptococcus species, moderate numbers of Prevotella species, and Bacteroides capillosus.

\section{Clinical Diagnosis}

The patient was suffering from an asymptomatic Acute Apical Abscess (AAA, Cellulitis/Phlegmon) with suppurative apical periodontitis and a cutaneous sinus tract emanating from tooth 47 (Figure. 3 and 4). 


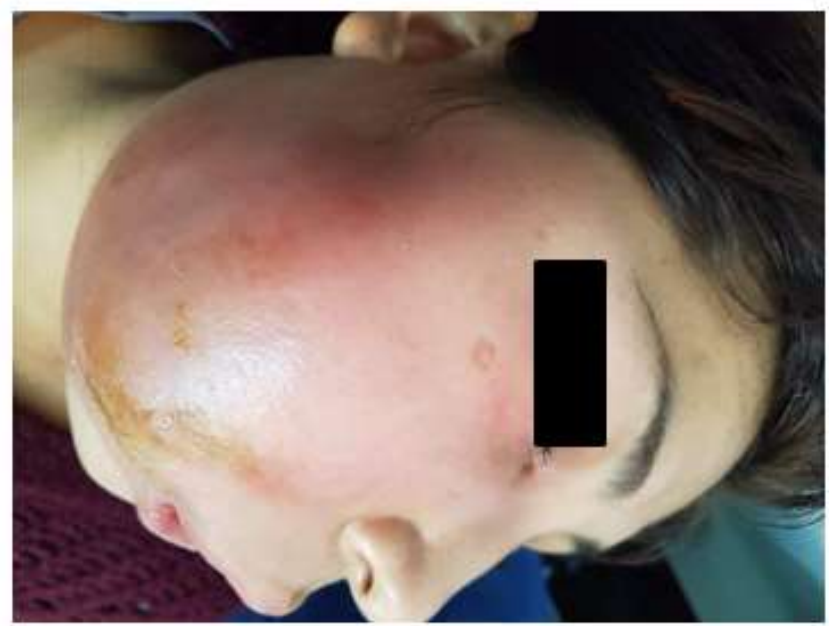

Figure 3. Preoperative extraoral view of the sinus tract in the facial region.

\section{Treatment protocol}

The clinical protocol for this case of AAA was a drainage of the cavity

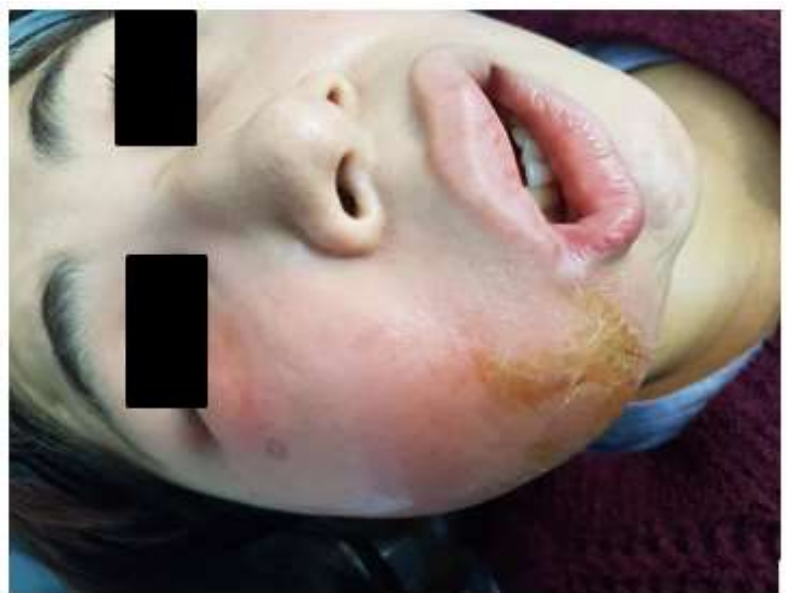

Figure 4: A cutaneous sinus tract confirming the presence of a large periapical radiolucent lesion associated with tooth 47 .

through the skin on two occasions, first: to give relief to the patient due to the pressure on the area (Figure. 5).

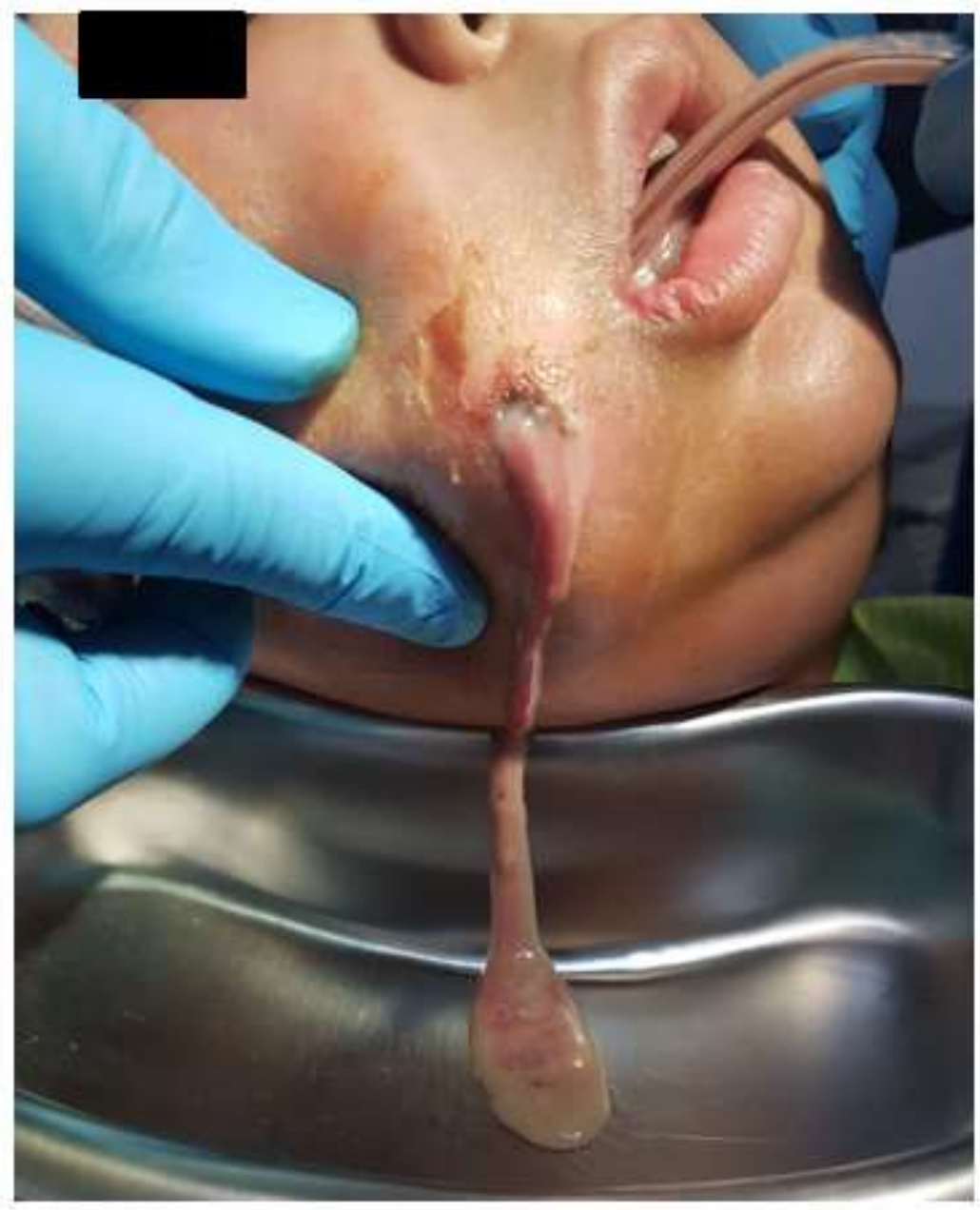

Figure 5: The patient was suffering from a symptomatic Acute Apical Abscess (AAA, Cellulitis/Phlegmon) with a suppurative apical periodontitis and a cutaneous sinus tract emanating from tooth 47. 
The patient was received and treated with extreme limitation in her oral opening.

After the first appointment, 1 gr of Ceftriaxona was administered every 24 hours for three days, Ixoprofeno of $60 \mathrm{mg}$ every 8 hours for four days, and Ketorolaco $10 \mathrm{mg}$ every 8 hours for four days [1, 5, 6].

In the second session, the phlegmon was drained and metronidazole of $500 \mathrm{mg}$ was administered every 12 hours for 7 days, as well as clindamycin of $350 \mathrm{mg}$ every 8 hours for seven days [6,7].

About a week later, the sinus tract was inactive. The patient confirmed a healing trend with a noticeable improvement in her mouth opening and the traces of the skin infection was improving. Once the patient was able to open her mouth, the oral surgeon extracted tooth 47 . Tooth 47 was pulled out and the sinus tract orifice healed. Radiograph revealed diminishment of the periapical lesion and thereby revealed some healing was occurring.

\section{Discussion}

In this clinical case, the cause of the cutaneous sinus tract was caused by extensive deep caries and an acute apical abscess. The complication for the patient was the development of an acute apical abscess also called cellulitis or phlegmon.

Persistent acute apical periodontitis led to the formation of a sinus tract. The evolution of the infection made that the tissues that surround the mouth and the cheek did not allow him to have a mouth opening to be treated orally. It is up to weeks after the cutaneous abscess was drained and the infection and pressure of the tissues reduced, plus the administration of drugs, allowed him to reduce his pain and inflammation [2].

In cases of an alarming odontogenic cutaneous sinus tract, patients usually consult a physician or dermatologist initially due to the absence of dental symptoms but with facial edema and increased temperature. It is very important to consider the dental reasons for inflammatory and persistent processes in the skin area of the face and neck. The unnecessary biopsies in the present case were performed twice and caused a delay in therapy and scars, so the patient should consult a trained dermatologist for their solution. Unfortunately, mistreatments in such cases are common [22, 23].

Correct diagnosis of a cutaneous sinus tract of dental origin can be detected by adequate oral diagnosis. The results of the histological examination of the odontogenic cutaneous sinus tracts were uneven [24]. The epithelial lining of the entire sinus tract is rarely produced, but it is frequently present in the skin openings. Most of the sinus tracts were not epithelialized and were only bordered by granulation tissue. It is commonly assumed that an epithelial lining can cause healing complications [24]. The therapy of cutaneous sinus tracts of dental origin consists of the removal of the infection source. After elimination of the reason for the infection by extraction of the tooth 47 .

When the infection is eliminated by the extraction of the tooth, immune systems act automatically, and the skin lesion will be accomplished with a dermatological or corrective procedure.

\section{Conclusion}

It is challenging to diagnose a cutaneous draining sinus tract of dental origin. Thus, treatment of skin lesions of the face (impetigo), and neck odontogenic infections should always be considered. Clinical and radiographic dental examinations can identify the tooth involved.

Auctores Publishing - Volume 6(1)-076 www.auctoresonline.org ISSN: 2578-8949

\section{References}

1. Siqueira, JF, Jr., Guimarães-Pinto, T, Rôças, IN. Effects of chemomechanical preparation with $2.5 \%$ sodium hypochlorite and intracanal medication with calcium hydroxide on cultivable bacteria in infected root canals. J Endod. 2007; 33:800-805.

2. Barrowman RA, Rahimi M, Evans MD, Chandu A, Parashos P. Cutaneous sinus tracts of dental origin. Med J Aust 2007; 186:264-265.

3. Cantatore JL, Klein PA, Lieblich LM. Cutaneous dental sinus tract, a common misdiagnosis: a case report and review of the literature. Cutis 2002;70:264-265.

4. Lubit FA, Senzer J, Rothenberg F. Extraoral fistulas of endodontic origin: report of two cases. J Endod 1976;2: 393-396.

5. Lewin-Epstein J, Taicher S, Azaz B. Cutaneous sinus tracts of dental origin. Arch Dermatol 1978; 114:11581161.

6. Spear KL, Sheridan PJ, Perry HO. Sinus tracts to the chin and jaw of dental origin. J Am Acad Dermatol 1983; 8:486-492.

7. Strader RJ, Seda HJ. Periapical abscess with intranasal fistula. Oral Surg Oral Med Oral Pathol 1971; 32:881884.

8. Tagami H, Yoshitake K. Chronic dental fistula on the nose.

9. Figdor, D, Sundqvist, G. A big role for the very small understanding the endodontic microbial flora. Aust Dent J. 2007; 52:S38-S51.

10. Ricucci D, Siqueira JF Jr. Recurrent apical periodontitis and late endodontic treatment failure related to coronal leakage: a case report. J Endod. 2011;37(8):1171-1175.

11. Siqueira, JF, Jr. Aetiology of root canal treatment failure: why well-treated teeth can fail. Int Endod J. 2001; 34:1-10.

12. Nair PN. Pathogenesis of apical periodontitis and the causes of endodontic failures. Critical Rev in Oral Biol \& Med 2004;15:348-381.

13. Ferraz CC, Gomes NV, Gomes BP, et al. Apical extrusion of debris and irrigants using two hands and three engine-driven instrumentation techniques. Int Endod J 2001;34(5): 354-358.

14. Bürklein S, Schëafer E. Apically extruded debris with reciprocating single-file and full-sequence rotary instrumentation systems. J Endod 2012; 38(6):850-852.

15. Schein B, Schilder H. Endotoxin content in endodontically involved teeth. J Endod 2006; 32:293295.

16. Martinho FC, Chiesa WM, Marinho AC, Zaia AA, Ferraz CC, Almeida JF, Souza-Filho FJ, Gomes BP. Clinical investigation of the efficacy of chemo mechanical preparation with rotary nickel-titanium files for removal of endotoxin from primarily infected root canals. J Endod 2010;36:1766-1769.

17. Dahlen G, Bergenholtz G. Endotoxic activity in teeth with necrotic pulps. J Dent Res.1980; 59:1033-1040.

18. Pereira RS, Rodrigues VAA, Furtado WT et al. Microbial analysis of root canal and periradicular lesion associated to teeth with endodontic failure. Anaerobe 2017; 48:12-18.

19. Watkins CA, Logan HL, Kirchner HL. Anticipated and experienced pain associated with endodontic therapy. J Am Dent Assoc 2002; 133(1):45-54. 
20. Paquette, L, Legner, M, Fillery, ED, et al. Antibacterial efficacy of chlorhexidine gluconate intracanal medication in vivo. J Endod 2007; 33:788-795.

21. Heling I, Rotstein I. A persistent oronasal sinus tract of endodontic origin. J Endod 1989; 15:132-134.

22. Bhaskar SN, Bernier SL. Histogenesis of branchial cysts: report of 468 cases. Am J Pathol 1959; 35:407423.

23. Johnson BR, Remeikis NA, Van Cura JE. Diagnosis and treatment of cutaneous facial sinus tracts of dental origin. J Am Dent Assoc 1999; 130:832-836.

24. Harris WE. Unusual endodontic complication: report of case. J Am Dent Assoc 1971; 8:358-363.

25. Kreutz RW, Carr SJ. Bilateral oronasal fistulas secondary to an infected maxillary subperiostal implant. Oral Surg Oral Med Oral Pathol 1986;61:230-232.

26. Shepherd JP. Osteomyelitis of the tibia following dentoalveolar abscess. Br Dent J 1978;145:267-268.
27. Purohit SD, Mathur BB, Gupta PR, Agarwal KC, Hathi HH. Tuberculous fistula of cheek. Oral Surg Oral Med Oral Pathol 1985;60:41-42.

28. Jacobs J, Shocket E. Dermal fistula of dental origin masquerading as a skin cancer. Oral Surg Oral Med Oral Pathol 1965;19:184-187.

29. Mahler D, Joachims HZ, Sharon A. Cutaneous dental sinus imitating skin cancer. Br J Plast Surg 1971;24:7881.

30. Goldstein BH, Sciubba JJ, Laskin DM. Actinomycosis of the maxilla: review of literature and report of the case. J Oral Surg 1972;30:362-366.

31. Craig RM, Andrews JD, Wescott WB. Draining fistulas associated with an endodontically treated tooth. J Am Dent Assoc 1984; 108:851-852.

32. Pasternak-Junior B, Teixeira CS, Silva-Sousa YTC, Sousa- Neto MD. Diagnosis and treatment of odontogenic cutane- ous sinus tracts of endodontic origin: three case studies. Int Endod J 2009; 42:271-276.
This work is licensed under Creative Commons Attribution 4.0 License

To Submit Your Article Click Here: Submit Manuscript

DOI: $10.31579 / 2578-8949 / 071$
Ready to submit your research? Choose Auctores and benefit from:

* fast, convenient online submission

* rigorous peer review by experienced research in your field

* rapid publication on acceptance

* authors retain copyrights

* unique DOI for all articles

* immediate, unrestricted online access

At Auctores, research is always in progress.

Learn more https://www.auctoresonline.org/journals/dermatologyand-dermatitis 